\title{
La metafísica medieval y la crítica de Heidegger a la ontoteología
}

\section{SILVANA FILIPPI}

CONICET - Universidad Nacional de Rosario

Pago Largo 464 - Rosario (Argentina)

sfilippi@unr.edu.ar

\begin{abstract}
Starting with Heidegger's critique of traditional metaphysics, according to which metaphysics is cast as "ontotheology", i.e., as the logic of being in general and of God in particular, this paper attempts to elucidate the pertinence of this critique to medieval metaphysics. The analysis shows that Heidegger, influenced by the perspective of late Scholasticism, errs in his interpretation of its doctrines, so that the aforementioned critique does not apply in generalized way.
\end{abstract}

Keywords: Metaphysics, Middle Ages, Heidegger, ontotheology.
Resumen: Dada la crítica heideggeriana a la metafísica tradicional, según la cual ésta se habría configurado como una "ontoteología”, es decir, una lógica del ente en general y de Dios en particular, este trabajo intenta dilucidar la pertinencia de tal crítica respecto de las metafísicas medievales. El análisis muestra que Heidegger, influido por una perspectiva propia de la Escolástica tardía, no acierta en su interpretación de tales doctrinas, a las que no cabría la mencionada crítica de modo generalizado.

Palabras clave: Metafísica, Edad Media, Heidegger, ontoteología. 


\section{SIGNIFICACIÓN Y ALCANCE DE LA CRÍTICA HEIDEGGERIANA}

\section{A LA "ONTOTEOLOGÍA"}

E s conocida la crítica heideggeriana a la metafísica occidental, a la cual, por su "olvido del ser" y por su "objetivación" de Dios, ha acusado de convertirse en una "onto-teo-logía", es decir, en una lógica del ente en general y de Dios en particular. Aunque inicialmente este calificativo le fue aplicado por Heidegger al sistema hegeliano, pronto se extendió a casi toda la historia de la metafísica e, incluso, a su esencia misma. Con raíces en la ambigua bivalencia de la metafísica aristotélica —al par ontología y teología- Heidegger considera que la confusión se trasladó sin más al pensamiento cristiano medieval, puesto que, a su modo de ver, no habría forma de explicar convincentemente el pasaje, asumido naturalmente en las metafísicas medievales, del estudio del ente en tanto ente a la reflexión sobre Dios.

Esta observación crítica de Heidegger aparece bastante tempranamente en su obra y, aunque fue modificando su formulación, un fondo común se percibe de principio a fin.

Ya en el curso sobre Kant de 1929 Kant und das Problem der Metaphysik hace alusión a "un curioso desdoblamiento en la determinación de la esencia de la filosofía primera" ${ }^{1}$, dado que ella es tanto conocimiento del ente en tanto que ente ( $\tau$ ó òv ị ôv) como co-

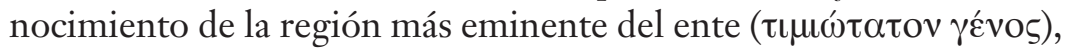
a partir del cual se determina el ente en su totalidad ( $x \alpha \theta$ ó $\lambda$ ov). Esta

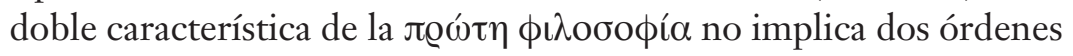
de ideas fundamentalmente diferentes e independientes, pero tampoco se puede reducir a la unidad. Se trata, pues, de

aclarar los fundamentos de esta aparente ambivalencia [Zwiespältigkeit] y la índole de la correspondencia entre ambas determinaciones a partir del problema conductor de una "filosofía primera" del ente. Esta tarea se vuelve tanto más apremiante cuanto que esa duplicación no aparece solamente en Aristóte-

1. M. HeIdegger, Kant und das Problem der Metaphysik, GA Bd. 3 (Klostermann, Frankfurt a. M., 1991) 7. 
les, sino que impera atravesando el problema del ser desde el inicio de la filosofía antigua ${ }^{2}$.

Con todo, poco después, en el curso de invierno de 1930-31 que dedica a la Fenomenología del Espíritu de Hegel, Heidegger parece aplicar el término "onto-teo-logía" en particular al sistema hegeliano, puesto que en él el saber absoluto de lo absoluto presupone una lógica, dialéctica y especulativa, capaz de reunirlo todo en la unidad de las contradicciones, mientras que, en consonancia con ello, el ser se identifica con Dios ${ }^{3}$. Sin embargo, en el mismo texto el filósofo de Friburgo no deja de recordarnos el lejano origen de esta cuestión, por lo que añade:

Sabemos también que ya Aristóteles puso en estrecha cone-

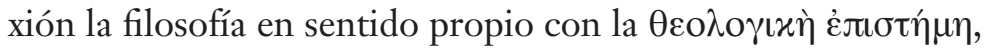
sin que estemos en condiciones de dar, en una interpretación directa, reales explicaciones sobre la relación entre la cuestión del ôv ทุ ôv y aquella del $\theta \varepsilon i ̂ o v$.

Con la expresión "onto-teo-logía” decimos que la problemática del óv, en tanto problemática lógica, está orientada en primera

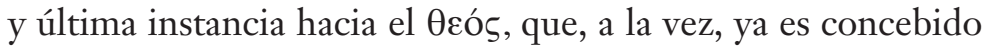
él mismo "lógicamente" $[\ldots]^{4}$.

El sistema hegeliano, entendido como onto-teo-logía en sentido estricto, aparece así como enraizado en un decurso histórico de larga data, respecto del cual su pensamiento no sería sino la culminación. Tanto que, a medida que Heidegger va madurando esta idea, su alcance se vuelve de vez en vez más amplio. Así, en la introducción añadida en 1949 a Was ist Metaphysik?, titulada Der Rückgang in den Grund der Metaphysik (El regreso al fundamento de la metafísica), es la metafísica, en sí misma y en general, la que muestra una constitución onto-teo-lógica:

2. Ibidem, 8 .

3. M. HeIdegger, Hegels Phänomenologie des Geistes, GA Bd. 32 (Klostermann, Frankfurt a. M., 1980) 141-143.

4. M. HeIDEgGer, Hegels Phänomenologie cit., 141-142. 
La metafísica es en sí, y precisamente porque lleva el ente en tanto ente a la representación de modo dual y uno [zwiefacheinig], la verdad del ente en general y por excelencia [im Allgemeinen und im Höchsten]. Ella es, según su esencia, a la vez ontología en sentido estricto y teología ${ }^{5}$.

Ahora bien, el filósofo alemán encuentra no simplemente un carácter propio de la metafísica en esa bivalencia, sino un verdadero problema irresuelto. De ahí que en un interesante pasaje de la conferencia Identität und Differenz de 1957, significativamente titulado "Die onto-theo-logische Verfassung der Metaphysik", da expresión a tal dificultad del siguiente modo: "el carácter onto-teológico de la metafísica ha devenido problemático para el pensamiento no en razón de algún ateísmo, sino a partir de la experiencia de un pensar al cual se ha mostrado, en la onto-teo-logía, la unidad todavía impensada de la esencia de la metafísica"

En efecto, lo que produce a Heidegger un profundo extrañamiento es que la metafísica pueda haber excedido los límites de la ontología y haberse convertido en teología, esto es, en "un discurso sobre Dios, porque el dios [der Gott] entra en la filosofía. Así, la cuestión del carácter onto-teológico de la metafísica se agudiza y deviene la cuestión: ¿cómo el dios entra en la filosofía, no solamente en la filosofía moderna, sino en la filosofía como tal?"

Obsérvese que la misma expresión ambigua "el dios" indica que Heidegger no cree que el tema de Dios haya ingresado a la filosofía recién con el advenimiento del pensamiento cristiano, sino desde la antigüedad griega, en el inicio mismo del pensar. Pero ¿por qué habría acontecido semejante fenómeno? En la perspectiva de nuestro autor, porque el ser se nos ha dado

5. M. HeIdegGer, Was ist Metaphysik? (Klostermann, Frankfurt a. M., $\left.{ }^{7} 1955\right) 19$.

6. M. Heidegger, Identität und Differenz (Neske, Pfullingen, 1957) 35-73 ("La constitución onto-teo-lógica de la metafísica").

7. Ibidem, 51 .

8. Ibidem, 52 . 
como el fundamento [Grund] productor [her-vor-bringenden], fundamento que, él mismo, a partir de lo fundado por él, necesita de una fundación [Begründung] adecuada a él, es decir de una causación por la cosa más originaria [die ursprünglichste Sache]. Ésta es la causa [Ursache] en tanto que causa sui. Ése es el nombre propio de Dios en la filosofía?.

No son pocos los estudiosos que han advertido aquí un yerro por parte de Heidegger dado que la concepción de Dios como causa de sí mismo es propia del sistema cartesiano que universaliza la noción de causa hasta someter a ella incluso al Creador, pero el principio de razón suficiente según el cual todo tiene una causa, de ningún modo es una tesis que haya sido sostenida por la filosofía precedente.

Tanto horror experimenta Heidegger ante esta concepción de la causalidad (a la que entiende como producción de cosas a partir de $\operatorname{cosas}^{10} \mathrm{y}$, en particular, a partir de Dios como "cosa suprema" ${ }^{11}$ ), que le parece la expresión máxima de la desacralización de Dios. En tal sentido, dice, "el pensar sin Dios [gott-lose] que necesariamente debe abandonar al Dios de la filosofía, al Dios como causa sui, está quizás más cerca del Dios divino"12.

Sin embargo, la traza histórica de la onto-teo-logía habría tenido según Heidegger tal magnitud que incluso la metafísica de Nietzsche, al parecer tan alejada de la "metafísica escolar" (Schulmetaphysik) sería al mismo tiempo una suerte de teología, aunque fuese

9. Ibidem, 70 .

10. La noción de causalidad, tal como ha sido comprendida por Heidegger, resulta una clave fundamental para explicar sus equívocos respecto de la metafísica medieval en general y de la metafísica tomasiana en particular. Si bien no nos extenderemos aquí sobre el tema, puede verse nuestro trabajo Causalidad y creación en la metafísica tomista. Notas sobre una equívoca interpretación heideggeriana, en L. CORSO de Estrada, M. J. Soto-Bruna, C. Alonso del Real (eds.), Figuras de la causalidad en la Edad Media y en el Renacimiento (EUNSA, Pamplona, 2017) 425-439. También puede consultarse G. LLACH, Heidegger y su interpretación del esse tomista, "Aporía. Revista Internacional de Investigaciones Filosóficas" 6 (2013) 47-58.

11. Heidegger juega con el sentido implícito en la palabra Ursache, la cual significa "causa" pero puede desdoblarse en dos componentes: Ur-Sache, lo que querría decir "proto-cosa" o "cosa originaria".

12. M. HEIDEGGER, Identität und Differenz cit., 71. 
negativa, al pensar la existentia del ente como tal en su totalidad como eterno retorno de lo mismo. La onto-teo-logía acaba pues, finalmente, en el nihilismo, ya que éste no consiste sino en el más profundo olvido del ser al buscar el fundamento del ente no en el ser mismo, sino en otro ente, un ente supremo, cuya naturaleza reside en constituir la proto-cosa o ente originario capaz de causar los otros entes y a sí mismo, sea cual fuere el sentido en que se entienda.

En palabras del propio Heidegger:

Si la metafísica como tal no piensa el ser mismo porque piensa el ser en el sentido del ente como tal, la ontología y la teología, ambas a partir de su mutua interdependencia, han de dejar impensado el ser mismo. La teología toma la essentia del ente a partir de la ontología. La ontología, a sabiendas o no, remite el ente respecto de su existentia, es decir como existente, al primer fundamento, que representa la teología. La esencia onto-teológica de la metafísica piensa el ente en la perspectiva de essentia y existentia. Estas determinaciones del ser del ente son en cierto modo sólo rozadas por el pensamiento, pero no pensadas a partir del ser mismo, ni cada una por sí ni ambas en su diferencia ${ }^{13}$.

Así, parece que el olvido del ser y la entrada en la filosofía de un discurso acerca de Dios entendido como ente supremo, productor de todo ente, serían, según Heidegger, las dos caras de la misma moneda: en lugar de hallar el fundamento del ente en el ser, el olvido del ser ha provocado la necesidad de encontrar en la figura del dios el ente supremo que se constituye en el principio causal de todo ente, incluido él mismo. De ahí que la metafísica oscile entre la ontología y la teología en una circularidad que se retroalimenta.

13. M. Heidegger, Nietzsche, Bd. II (Neske, Pfullingen, 1961) 348-349. En efecto, el pensador alemán considera que la distinción de esencia y existencia no excede por sí misma el plano del ente, pues la essentia indica lo que el ente es, mientras que la existentia apunta al ente en su presencia efectiva, pero ninguna de ambas nociones expresaría por sí el ser como tal (esse), sino que se fundan veladamente en él. 


\section{A esta altura resulta difícil no pensar en las consecuencias que} traería para las metafísicas medievales esa generalizada acusación de Heidegger a la metafísica ${ }^{14}$, dado que, presuntamente, ni siquiera la

14. Ya desde la segunda mitad del siglo XX ha habido pensadores que se han ocupado de analizar y, muy frecuentemente, de rectificar críticamente, la singular lectura heideggeriana del pensamiento medieval, particularmente, en lo que concierne a la metafísica de Tomás de Aquino y su noción capital de actus essendi. Entre ellos se encuentran, además de las acreditadas voces de É. GILSON —recordemos sus Constantes philosophiques de l' être (Vrin, Paris, 1983) — y C. FABRO — por ejemplo en L'interpretazione del'atto in S. Tommaso ed Heidegger (Edizioni Domenicane Italiane, Napoli, 1975) y Santo Tomás frente al desafío del pensamiento moderno, en C. FABRo et al., Las razones del tomismo (EUNSA, Pamplona, 1980) 15-45-, un buen número de estudiosos entre los que se cuentan: J. STALlmaCH, Der actus essendi bei Thomas von Aquin und das Denken der "ontologischen Differenz", "Archiv für Geschichte der Philosophie" 50/1-2 (1968) 134-144; M. MüLler, Sein und Geist. Systematischen Untersuchungen über Grundprobleme und Aufbau mittelalterliche Ontologie (Mohr, Tübingen, 1940), 2a ed. ampliada con la contribución Die Aktualität des Thomas von Aquin (Karl Alber, Freiburg/München, 1981); G. SIEWERTH, Das Schicksal der Metaphysik von Thomas zu Heidegger (Johannes Verlag, Einsiedeln, 1959); B. Rioux, L'être et la vérité chez Heidegger et Saint Thomas d'Aquin (Presses de l'Université de Montréal-Presses Universitaires de France, Montreal, Paris, 1963); J. LOTZ — quien incluso fuera discípulo de Heidegger-, Heidegger und Thomas von Aquin (Herder, Freiburg, 1975); A. DONDEYNE, La différence ontologique chez M. Heidegger, "Revue Philosophique de Louvain" 56, 49 (1958) 35-62; J. D. CAPuTO, Heidegger and Aquinas. An essay on overcoming metaphysics (Fordham University Press, New York, 1982); J.-L. MARION, Dieu sans l'être (Fayard, Paris, 1982-rééd. PUF, Paris, 2010); J.-F. CourTine, Heidegger et Thomas d'Aquin, en C. Esposito, P. Porro (eds.), Heidegger e i medievali. Quaestio. Annuario di storia della metafisica 1 (2001) 213-234, y también, Inventio analogiae. Métaphysique et ontothéologie (Vrin, Paris, 2005), especialmente la Première partie. En Argentina se han ocupado ya tempranamente de la cuestión, por ejemplo, O. N. DERISI - Reflexiones acerca del sentido del esse en Santo Tomás frente a la concepción respectiva en Aristóteles, en la Escolástica y en Heidegger, "Sapientia" (La Plata) 14 (1959) 289292; El ser en Heidegger y Santo Tomás (EUDEBA, Buenos Aires, 1968); El último Heidegger. Aproximaciones y diferencias entre la fenomenología existencial de M. Heidegger y la ontología de Santo Tomás (EUDEBA, Buenos Aires, 1968, Col. Ensayos)— y R. ECHAURI, entre otros escritos, en La diferencia ontológica en Heidegger y Santo Tomás, "Philosophia" 28 (1964) 15-28; Heidegger y la metafísica tomista, con Prefacio de É. GILSON (EUDEBA, Buenos Aires, 1971); Heidegger y el esse tomista, "Cuadernos de Filosofía” XI/15-16 (1971) 207-214; Sobre una nueva confrontación de Heidegger con Santo Tomás, "Sapientia" 42 (1987) 371-380; Esencia y existencia (CUDES, Buenos Aires, 1990). Este listado, en absoluto exhaustivo, basta para mostrar la pluralidad de aportes a la cuestión, tanto en Europa como en América. Conviene notar que no ha habido entre estos estudiosos una coincidencia plena en todo respecto, pero, no obstante, sus opiniones acuerdan en que Heidegger, influido por la Escolástica tardía, habría cometido importantes errores de interpretación respecto de la metafísica tomista y, sin embargo, el análisis de su pen- 
común distinción de esencia y existencia en el ente creado las salvaría de haber olvidado el ser mismo ${ }^{15}$ y de convertir a Dios en un ente supremo cuya función principal consiste en explicar, en cuanto causa, la producción de todo ente.

\section{LA CONCEPCIÓN DE DiOS EN LAS METAFÍSICAS MEDIEVALES: ¿FUENTE U OBJETO?}

En primer lugar, podría preguntarse si la mencionada bivalencia de la metafísica tradicional puede ser hallada realmente en Aristóteles. Dado que Heidegger omite toda referencia a la génesis de su Metafísica, no del todo esclarecida, y a las dificultades filológicas que aún subsisten para comprenderla en su unidad, parecería que la remisión de la cuestión al Estagirita es cuando menos problemática. Sin embargo, y en favor del filósofo alemán, es cierto que la tradición metafísica aristotélica que ha llegado hasta nosotros, indudablemente atravesada por una multiplicidad de modificaciones introducidas por sus seguidores y teñida de influencias doctrinales ajenas al propio Aristóteles, nos ha legado la concepción de la metafísica como referida al ente en su totalidad y al ente supremo en particular. En tal sentido, dice Heidegger:

En Aristóteles, por tanto, encontramos prefigurada esta peculiar conexión entre la prima philosophia y la teología. Sobre la base de esta conexión, mediada por una determinada interpretación de la filosofía árabe, en el medioevo, cuando aquella fue conocida por medio de Aristóteles, y sobre todo por medio de sus escritos

samiento, suficientemente evidenciado en sus yerros, puede dar lugar a una eficaz renovación de los estudios metafísicos. Últimamente, en parte vinculada a la aparición de nuevos títulos dentro de la edición de la Gesamtausgabe heideggeriana, la tendencia ha sido ampliar la confrontación de la exégesis heideggeriana con la tradición metafísica más allá de lo que refiere puntualmente a la metafísica tomista, extendiéndola a la historia de la metafísica en general; tal el caso de estudiosos como J.-F. Courtine, C. Esposito y O. Boulnois. Uno de los logros de esta línea de investigación reside, sin duda, en que ha contribuido a aportar mayor claridad a la trama entera de la metafísica desde sus orígenes griegos hasta la actualidad.

15. Véase la nota precedente. 
metafísicos, resultó facilitada la adaptación del contenido de la fe cristiana al contenido filosófico de los escritos de Aristóteles $^{16}$.

A la no aclarada vinculación aristotélica entre metafísica como estudio del ente en tanto ente y teología natural (theologia naturalis o scientia divina) como discurso acerca del ente supremo o divino se agrega en el pensamiento cristiano la presencia de la teología sobrenatural (sacra doctrina o sacra pagina). A los autores cristianos no les parecía en absoluto descabellado que Dios pudiese ser al par motivo de fe y de especulación racional, como tampoco encontraron dificultad en vincular el estudio del ente en tanto ente con la reflexión natural en torno a Dios.

Pero ¿cómo ha de ser entendida tal duplicidad? ¿Existe un único modo en que las metafísicas medievales se apropiaron de tal tradición filosófica de origen griego?

Olivier Boulnois, en un trabajo excepcionalmente rico y equilibrado ${ }^{17}$, ha intentado desbrozar, bajo la universalidad de la crítica heideggeriana, la especificidad de al menos tres tipos de metafísicas medievales en las que la tradición de la metafísica aristotélica estaría presente de modos bien diferenciados.

Ya a comienzos del siglo XIII es posible advertir una primera forma histórica de tal metafísica en la definición escolar que la considera "ciencia divina de lo divino", es decir, como ciencia de aquello que se halla separado de la materia y del movimiento. El corpus aristotélico al que en este caso se remite es diferente del que hoy consideramos tal, no sólo porque se advierte la falta de algunos libros que actualmente contiene la Metafísica, sino, sobre todo, porque se incluye en ella, como su culminación, el Liber de causis de raigambre patentemente neoplatónica. Así, a la tradicional demostración aristotélica de la existencia de un primer principio se le ha añadido una teología des-

16. M. HeIDEgGER, Grundbegriffe der Metaphysik. Welt-Endlichkeit-Eisamkeit, Freiburger Vorlesung WS 1929/30, GA Bd. 29/30 (Klostermann, Frankfurt a. M., 1983) 65.

17. O. Boulnois, Heidegger, l'ontothéologie et les structures médiévales de la métaphysique, en C. EsPosito, P. Porro (eds.), Quaestio 1. Heidegger e i medievali (BrepolsPagina, Turnhout-Bari, 2001) 379-406. 
cendente que muestra la emanación de la totalidad de lo real desde lo divino. La metafísica, pues, ya no es entendida como ciencia del ente en tanto ente, sino lisa y llanamente como teología, dado que en su desarrollo, a la vez ascendente y descendente, lo que verdaderamente importa es mostrar la existencia y naturaleza misma de lo divino. Más allá de Aristóteles, esta metafísica, estrechamente ligada al corpus de las traducciones greco-árabes, retoma la doctrina aristotélica sobre el primer motor, pero puesto que para entonces nos encontramos en un contexto creacionista, la amplía en el sentido de una teoría sobre el primer agente, para, finalmente, mostrar el proceso de emanación como donación del ser a partir de ese primero.

Este proyecto supone una distinción entre dos sentidos de la causa, la causa motriz y el principio del ser. El primer motor no se identifica con el "primer agente" (Primum agens); en efecto, [el primer motor] es alcanzado al término de una prueba que sigue siendo físico-teológica; suponiendo que sea Dios, es el Dios de los físicos. Por el contrario, el Dios verdaderamente Dios es creador del ser, y por ello es verdaderamente el objeto de la metafísica ${ }^{18}$.

En el movimiento del ser de lo creado hacia la realidad divina y de ésta nuevamente al ser de lo creado, se hace manifiesta la existencia y la actividad creadora de lo divino. En esta versión cristiano-latina de la metafísica aristotélica late indudablemente la labor previa de los filósofos árabes quienes, hacia el siglo IX, elaboraron una Theologia Aristotelis en donde la supuesta doctrina del Estagirita aparece ligada a fuertes motivos neoplatónicos y, naturalmente, a una concepción de la causa eficiente y de la emanación sobre el trasfondo de un horizonte creacionista, destinada a poner de manifiesto la "soberanía de lo divino". Así, en esta particular versión de la metafísica como teología, Dios aparece como su sujeto no en razón de su representación objetivante por parte de una ontología que lo sometiese a sus propios principios, sino como absorción de aquélla en el seno de

\section{Ibidem, 392.}


una teología. Esta forma de la metafísica fue adoptada por el pensamiento cristiano en buena medida por su consonancia con la fe en un Dios único y creador del universo, pero, es preciso observarlo, el origen de su soporte conceptual ya había sido formulado, en otro contexto y por distintos motivos, por la metafísica teologizante de los neoplatónicos. Por eso, los autores cristianos más fuertemente influidos por el neoplatonismo, sea antes o después de la irrupción del corpus aristotélico, desde Dionisio y Escoto Erígena a Buenaventura, Meister Eckhart y Nicolás de Cusa, han adoptado, en general, alguna variante, en cada caso más o menos pronunciada, de esta subsunción de la ontología en la teología.

Con respecto a esta forma de la metafísica no puede hablarse patentemente de onto-teo-logía en sentido heideggeriano: simplemente la metafísica ha devenido teología, de tal modo que en ella quedan reabsorbidas la ontología y la lógica misma.

Hay, sin embargo, otra forma histórica mediante la cual se ha difundido la herencia metafísica aristotélica en el medioevo. Con raíces también árabes, en esta otra versión, la metafísica no puede tener como sujeto de su competencia a Dios. Avicena ya había observado que toda ciencia presupone la existencia de su sujeto, la cual debe ser demostrada en otro ámbito, pues: "Nulla enim scientia debet stabilire esse suum subiectum" ${ }^{19}$. Ahora bien, no hay ciencia que pueda proveerle a la metafísica de una demostración de tal tipo porque la prueba aristotélica en torno a un primer motor no deja de ser una prueba física que no alcanza al Dios único y creador como primer agente. La física, pues, no puede superar el plano de las causas últimas del movimiento para proporcionar la demostración del Dios de la creación. Por tanto, parece que esta noción de metafísica retoma la línea aristotélica expuesta en el libro $\Gamma$ según la cual esta ciencia no puede versar sino sobre el ente en tanto ente y las propiedades que como tal le corresponden: "Ideo primum subiectum huius scientiae est ens inquantum est ens; et ea quae inquirit sunt consequentia ens inquantum est ens sine conditione" ${ }^{20}$.

19. AviCENA, Liber de philosophia prima, sive scientia divina, I, 1, 5.

20. AVICENA, Liber de philosophia prima, I, 2, 13. 
Ahora bien, si la metafísica versa sobre el ente en tanto ente, entendido en su más amplia generalidad, aún nada se ha dicho sobre el principio absoluto al cual el ente finito le debería su estar siendo. ¿Es que Dios ha quedado excluido de la metafísica o es que ha de ser comprendido como un ente más?

Una de las posibles respuestas a este interrogante ha sido proporcionada de modo eminente por Tomás de Aquino. Heidegger mismo repara particularmente en esta explicación, aunque ni la comprende ni la encuentra satisfactoria.

Esa respuesta del Aquinate se encuentra especialmente condensada en el Proemio de su Comentario a la Metafísica de Aristóteles $^{21}$. Allí se habla de una scientia regulatrix en la cual, según el Friburgués, se incluirían en confusa superposición 1) la philosopbia prima, que trata de las causas primeras de las cosas (las cuales, para Heidegger, finalmente se reducen a la causa prima, es decir, a Dios considerado por la fe como creador del mundo ${ }^{22}$ ), 2) la metaphysica, que trata del ente en general y de los principios universales que le inhieren en cuanto tal, y 3) la theologia, que versa sobre las sustancias completamente separadas de la materia sensible, vale decir, Dios y las inteligencias angélicas.

Ahora bien, pregunta Heidegger, ¿cómo se articulan entre sí estas tres modalidades de conocimiento de lo máximamente inteligible? Y, sobre todo, ¿cómo se relaciona la ciencia que trata del ente en general con aquella que, según la interpretación cristiana, se ocupa de la creación del ente por parte de un ente sumo que es causa primera? Ambas direcciones de la indagación apuntan hacia aquello que es supremo y último, pero según dos sentidos completamente diferentes y sin que se haga el intento de tomarlos en su posible unidad ${ }^{23}$.

21. Tomás de Aquino, In duodecim libros Metaphysicorum Aristotelis expositio (Marietti, Torino-Roma, 1950), "Proemium", 1.

22. M. HeIDEgGER, Grundbegriffe der Metaphysik cit., 71: "Diese [die causa prima] aber ist, wie durch den Glauben gesagt wird, Gott als Schöpfer der Welt".

23. Ibidem, 77 . 
Nótese en lo antedicho cómo Heidegger juzga el vínculo causal entre Creador y creatura como restringido al ámbito de $\mathrm{la}_{\mathrm{fe}}{ }^{24} \mathrm{y}$, en consecuencia, como un elemento extrínseco y extraño a la metafísica. Sin embargo, la concepción del primer principio como fuente del ser y el existir de todo lo creado no es históricamente exclusiva de la fe cristiana. Conceptualmente, sostiene Boulnois, ya había sido enunciada, en sentido emanacionista, por el neoplatonismo, al cual Heidegger o bien desestima o, quizás, resta carácter filosófico considerándolo sólo teosofía.

Por tanto, concluye el estudioso francés, la crítica heideggeriana es doble: por un lado, parece que bajo la formulación tomista las determinaciones de la metafísica son incoherentes; por otro, que ellas no forman un conjunto más que por la unidad de una teología revelada ${ }^{25}$.

No obstante, además de lo apuntado por Boulnois acerca del emanacionismo neoplatónico, también se ha observado que la pregunta misma por un origen radical de la totalidad del ente ya había sido formulada desde el inicio del pensar en el poema de Parméni$\operatorname{des}^{26}$ al margen de que su respuesta fuese finalmente negativa. Claro que si, por un lado, la concepción neoplatónica de la emanación no es idéntica al creacionismo judeo-cristiano, por otro, la descripción tomista de la ciencia metafísica y de la primera causa se encuentra lejos de desconocer sus raíces bíblicas, las que, por lo demás, le aportan su carácter específico; mas, lo que se quiere decir, es que no

24. En efecto, para Heidegger, Dios resulta considerado por Tomás de Aquino como creador del mundo exclusivamente en razón de su cristianismo, de tal manera que la scientia regulatrix a la que refiere el maestro medieval al comentar a Aristóteles estaría "esencialmente determinada por la fe" (wesentilich bestimmt durch den Glauben). Ibidem, 74.

25. O. BoulnoIs, Heidegger, l'ontothéologie cit., 396.

26. Efectivamente, Parménides indaga el origen radical del ente, para preguntar, a continuación, qué necesidad lo habría hecho surgir antes o después (fr. 8). Como se sabe, finalmente sostendrá que la totalidad de lo que es es inengendrada. Sin embargo, la pregunta ha sido planteada y desde un horizonte filosófico. Históricamente descubierta de hecho a partir de la revelación bíblica, no es imposible que la noción de creación ex nibilo hubiese sido propuesta por la razón natural. Cfr. R. ECHAURI, Parménides y el ser, "Anuario Filosófico" 6 (1973) 106109 de 98-115; del mismo autor también puede consultarse: Sobre el origen del ser y la nada, "Acta Philosophica" 3/2 (1994) 315-325. 
es inconcebible pensar la creación como una exigencia de la razón natural ni pensar la totalidad de lo real en relación con un primer principio desde un horizonte exclusivamente filosófico.

Por otra parte, la concepción tomista de la metafísica no está viciada de incoherencia o confusión, sino que se funda claramente en una determinada tesis acerca del ser: aquella según la cual todos los entes tienen el esse commune, el que, por su carácter finito, proviene de Dios, quien al crear dona el ser a todas las cosas. Esto implica, a su vez, que Dios mismo no es un ente entre otros, aunque supremo, que pueda ser objeto especial de la metafísica, sino que se encuentra más allá de los entes finitos como la fuente de su ser (fons essendi). Por ello: "Causa prima est supra ens, in quantum est ipsum esse infinitum"27. Desde esta óptica, nuestro intelecto sólo es apto para el conocimiento del ente finito que participa del ser, pero no del ser mismo que resulta inapresable en conceptos y que es Dios mismo. El ser primero (ipsum purum esse) ha de resultar comprendido como fuente y razón de ser de todo lo que tiene el ser (babens esse), pero él mismo permanece inaccesible en su esencia. Tal como lo expresaba Maimónides, a quien Tomás ha tenido muy en cuenta: "Sólo alcanzamos de Él que es, pero no lo que es" ${ }^{28}$. El estudio del ente en tanto ente, no engloba, pues, en sentido estricto, el ser divino como si fuese parte de su objeto, sino como fuente y principio de la totalidad de lo real. "El ser no queda encerrado en un concepto, pues está abierto a su rebasamiento en lo divino" 29 .

Es evidente, entonces, que las nociones filosóficas de participación y de causalidad - la una de origen platónico, la otra aristotélico - se aúnan en la doctrina tomista para designar lo mismo: la procedencia de todo ente finito a partir del ser divino, que no puede ser concebido, él mismo, ni como causa de sí ni como ente en sentido estricto, pues se trata aquí del ser pleno e ilimitado. Dios no es, para Tomás, ni causa sui ni una Ur-Sache. Por lo demás, si puede subsistir aún alguna duda respecto de la conjunción de filo-

27. Tomás DE AQuino, In librum de Causis expositio, lectio 6.

28. Maimónides, Guía de los perplejos, 3 vols., versión española de León Dujovne (Consejo Nacional para la Cultura y las Artes, México, 1993), vol. I, cap. 58.

29. O. BoulnoIs, Heidegger, l'ontothéologie cit., 396. 
sofía primera y teología en Aristóteles, resulta insostenible presentar la concepción tomista de la metafísica como confusa o incoherente. Sus raíces bíblicas son tan patentes como su mismo fundamento metafísico consistente en una distintiva concepción del ser del ente como actus essendi recibido por participación a partir de la causa primera: el ipsum purum esse subsistens. La teología revelada no aparece aquí como zurcido artificioso entre dos concepciones distintas de la metafísica, sino como iluminada por una explicación racional, plena, ella misma, de sentido propio.

[...] la intervención de la teología no ha sido, como afirmó [Heidegger], un motivo externo guiado por la fe para completar la metafísica como ciencia, sino, al contrario, el indicio de un obstáculo epistemológico, la trascendencia de Dios, que fue formulado filosóficamente en el neoplatonismo y no solamente en una teología revelada ${ }^{30}$.

Probablemente, Heidegger haya quedado demasiado anclado en la anquilosada concepción de la doctrina tomista como "aristotelismo”, pues más allá de Aristóteles y más allá de toda otra influencia filosófica, Tomás ha encontrado, sin lugar a dudas, su propio camino metafísico.

Sin embargo, el pensamiento medieval dista mucho de ser uniforme, de modo que al menos una tercera forma histórica de la metafísica se recorta sobre su horizonte: aquella que se funda sobre otra modalidad de recepción del aristotelismo.

\section{LA ESCOLÁSTICA TARDÍA Y LA TRANSFORMACIÓN DEL PENSAR SOBRE DIOS}

Esa versión de la metafísica parece haber tenido su origen en el seno del averroísmo latino y en oposición a la doctrina tomista. Quien la habría delineado sería Siger de Brabante según el cual "no hay principio del ente en tanto ente, pues en ese caso todo ente tendría

30. Ibidem, 404. 
un principio" 31 , pero es evidente que Dios, el ente supremo, no lo tiene porque es incausado. Por tanto, resulta menester concluir que el objeto de la metafísica es la totalidad del ente dejando de lado la consideración de un principio causal trascendente, dado que Dios mismo es ente y parte de esa totalidad. Dios queda así incluido en el sujeto de la metafísica, que a partir de ahora no es más el ente creado, participante de su causa, sino el concepto de ente tomado de una manera indistinta, de modo que también puede abarcar a Dios, el principio del ente creado.

Frente a la indeterminación aviceniana, Tomás eligió privilegiar la causalidad, sometiendo el ens commune a la creación divina. Al contrario, Siger elige privilegiar la universalidad, sometiendo la causalidad creadora del principio a la generalidad del ente: la totalidad del ente comprende a Dios, que es sin causa [...] La universalidad del ente, como objeto primero del intelecto, se impone sobre la trascendencia del principio. La metafísica se cierra cuando incluye en sí a Dios ${ }^{32}$.

Sin embargo, un cambio fundamental subyace a esta nueva concepción de la metafísica, y es que Dios no es concebido por Tomás como ente supremo sino como ipsum esse, como el ser mismo, mientras que es recién en esta nueva versión de la metafísica que Dios aparece como ente supremo, protocosa o protocausa en el orden del ente (Ursache), razón por la cual puede ser integrado a la totalidad del ente en su más amplia generalidad. Es, en todo caso, sobre la base de este peculiar "olvido del ser" que despunta la conversión de Dios en objeto representable por la metafísica. El carácter de onto-teo-logía no puede ser achacado a la esencia general de la metafísica, cuando, en verdad, sus presupuestos aparecen tardíamente en la historia del pensar.

31. Siger de Brabante, Quaestiones in Metaphysicam (ed. C. A. Graiff, Éditions de l'Institut Supérieur de Philosophie, Louvain-la-Neuve, 1948) 5; cfr. In Metaphysicam IV Commentarium, ed. W. DuNPHY (Éditions de l'Institut Supérieur de Philosophie, Louvain-la-Neuve, 1981) 170.

32. O. BoulnoIs, Heidegger, l'ontothéologie cit., 398-399. 
Tal posición se consolidó progresivamente en las doctrinas de Juan Duns Escoto y de Francisco Suárez, quien la legó de modo decisivo a todo el pensamiento moderno, desde Descartes a Hegel, pasando por Kant, dado que sus Disputationes fueron, en lo sucesivo, el manual de metafísica más utilizado por largo tiempo.

Efectivamente, Duns Escoto ha pensado la cuestión metafísica de modo radicalmente diferente al Aquinate. Para aquél el objeto de la metafísica ha de ser el concepto unívoco de ens bajo cuya generalísima indeterminación es posible incluir todo lo que es, comprendiendo a Dios mismo:

En lugar de pensar a Dios como el ipsum esse, donante del ser, habrá que combinar el concepto común de ente con una diferencia: Dios es ens e infinitum. La conjunción de dos determinaciones implica que Dios sea descripto, es decir, casi definido, y más determinado que en el concepto universal de ente ${ }^{33}$.

Por ello, argumenta Duns Escoto, “condiciones principales concludendae de primo ente sequuntur ex proprietatibus entis inquantum ens. Speciales enim condiciones entis non concludunt primo aliquid de ipso ideo [metaphysica] tantum considerat de ente in communi" ${ }^{34}$. Siendo así, es natural que la reflexión acerca de Dios aparezca como parte especial de una metafísica general comprendida como ciencia trascendental, es decir, que versa sobre los conceptos comunísimos referidos al ente, entendido también como concepto unívoco y omniabarcante. La generalidad del concepto ha devorado pues, al par, la trascendencia del ser como principio y la singularidad existencial de los entes creados.

Sin embargo, quien acaba por sistematizar esta concepción metafísica, tras los pasos de Duns Escoto, ha sido propiamente Suárez. En su doctrina se cumple plenamente la articulación entre una

33. Ibidem, 400.

34. Juan Duns Escoto, Quaestiones in Metaphysicam I, q. 1, n. 43, 142, ed. G. ETZKORN et al. (St. Bonaventure University, The Franciscan Institute, St. Bonaventure, NY, 1997) 65. 
ontología neutra y una teología subordinada a aquella como una metafísica especial respecto de la general.

Semejante cambio se perfila en Suárez ${ }^{35}$ desde la misma presentación de sus Disputationes metaphysicae ${ }^{36}$, donde el teólogo de Granada expresa su propósito de no atenerse al comentario de la Metafísica aristotélica, como había sido tradición en el medioevo, sino de exponer las principales cuestiones servato doctrinae ordine. Este objetivo, aparentemente organizativo, en el fondo preanuncia la elaboración suareciana de una metafísica autónoma y sistemática que, partiendo de principios propios, a priori, es capaz de incluir también el objeto de la teología. Por tal razón, el lazo existencial entre Creador y creatura aparece ciertamente presupuesto desde el punto de vista de la fe, pero desde la óptica filosófica se intenta considerar tanto a la creatura como al Creador exclusivamente valiéndose de una noción unívoca de ente que, siendo resultado de una abstracción lógica, permita un tratamiento a priori de sus principios constitutivos. La ontología se vuelve, entonces, ciencia trascendental del ente en cuanto ente, entendida como ciencia de la pura esencia o posibilidad, que precede y sostiene el estudio de los entes particulares existentes, entre los cuales reingresa el mismo Dios, el cual, aun siendo el ente supremo, resulta también concebido como un ente bajo el concepto general de ens ut sic. Luego, concluye Suárez, "absolutamente Dios cae bajo el objeto de esta ciencia" ${ }^{37}$. Y agrega más adelante: "Hay que decir, por tanto, que el ente, en cuanto ente real, es el objeto adecuado de la metafísica"; pero, además, "el objeto adecuado de esta ciencia debe abarcar [comprehendere] a Dios y a las otras sustancias inmateriales" ${ }^{38}$. La

35. Cfr. C. Esposito, Ritorno a Suárez. Le Disputationes Metaphysicae nella critica contemporanea, en La Filosofia nel Siglo de Oro. Studi sul tardo rinascimento spagnolo (Levante Editori, Bari, 1995), 465-573. ID., Heidegger, Suárez e la storia dell'ontologia, en C. Esposito, P. Porro (eds.), Quaestio 1. Heidegger e i medievali (Brepols-Pagina, Turnhout-Bari, 2001) 407-430.

36. Francisco Suárez, Disputaciones metafísicas, ed. bilingüe a cargo de S. Rábade Romeo, S. Caballero Sánchez, A. Puigcerver Zanón (Gredos, Madrid, 1960-1967) 7 vols.

37. Ibidem, I.1.19, vol. I, 225: "ergo absolute Deus cadit sub obiectum huius scientiae”. El énfasis es nuestro.

38. Ibidem, I.1.26, vol. I, 230. 
metaphysica generalis (ontología) se completa, pues, con una metaphysica specialis (teología).

En un ambiente doctrinal en el que, desde hacía algún tiempo, se desconfiaba del dato sensible y de los entes singulares para llegar a la constitución inteligible de lo real, parecía en consecuencia necesario partir del dato mismo de la razón para poder acceder a lo suprasensible. Por eso, al afirmar que la teología divina y sobrenatural halla su "acabamiento" o "cumplimiento" (perficitur) en el discurso y raciocinio humano ${ }^{39}$, impensadamente, Suárez sometía el misterio de la fe a la racionalización de una metafísica autónoma y propensa a la reductibilidad lógica de la existencia concreta de lo real, en tanto adopta como punto de partida la prescindencia del carácter creatural del ente y la reducción del Creador a mero "objeto especial" de ese pensamiento. A partir de ahora, la metafísica no necesitará presuponer el vínculo existencial entre Dios y la creación, es decir, la causalidad y la doctrina de la analogía, sino que partirá de principios propios, a priori, capaces de abarcar en sí la totalidad de lo real, incluido el mismo Ser divino. Así, aunque Dios sea el objectum praecipuum, el objeto principal de la metafísica, su objectum adaequatum es el ens in quantum ens que resulta definido, a su vez, como conceptus entis, como objeto puramente pensado, formal y neutro. El objeto de la metafísica, lo "real", ya no es, por tanto, un datum, algo dado en el orden existencial y dependiente de su causa, sino ante todo un cogitatum, algo pensable, reductible a términos de pura razón. La causalidad y Dios como fuente del existir permanecen como algo extrínseco a la metafísica.

Así, dice Suárez que

- al concepto formal de ser responde un solo concepto objetivo adecuado e inmediato que no significa expresamente ni la sustancia, ni el accidente, ni a Dios, ni a la creatura, sino que significa todas estas cosas como si fueran una sola, a saber, en cuanto son de algún modo semejantes entre sí y convienen en ser- ${ }^{40}$.

39. Ibidem, "Proemio", vol. I, 203.

40. Ibidem, II.2.8, vol. I, 377. 
Se aprecia, entonces, que las dos grandes cuestiones metafísicas, la del ente en común y la de Dios, son comprendidas aquí en un sentido completamente diferente al de la doctrina tomasiana, puesto que ambas resultan subsumidas bajo una noción de ens ya no entendido como aquello que tiene el ser (babens esse) y lo ha recibido por participación de su causa (ipsum esse), sino como concepto neutro y a priori. Por eso, en Suárez, incluso el ente actualmente presente constituye un caso particular de la esencia real, es decir, de la realitas concebida como esencia pensable de modo no contradictorio ${ }^{41}$. El orden de la existencia concreta cede paso al orden de los principios lógicos. Epistemológicamente, la metafísica prescinde de la condición existencial del ente para considerar a priori ${ }^{42}$ su configuración eidética más allá del hecho de que exista actualmente o no. La logicización del pensar sobre el ente y la reducción de Dios a objeto de ese pensar son ya manifiestas. En esta doctrina, incluso más allá de la intención de su autor, se afianzaba la constitución onto-teológica de la metafísica. Francisco Suárez, ha sido, en verdad, quien ha sentado, probablemente de modo involuntario, los principios de la onto-teo-logía, esto es: la exclusión de la relación creatural entre Dios y los entes finitos, y, en consecuencia, el comprender a Aquél no como fuente del ser, sino como objeto de una metafísica especial.

\section{LA PARADOJA HEIDEGGERIANA RESPECTO \\ DE LA FILOSOFÍA MEDIEVAL}

Conocido por Heidegger ya desde su temprana formación teológico-filosófica, Suárez ha sido considerado por el filósofo de Friburgo no sólo una figura clave para comprender el pensamiento moderno, sino que, además, ha señalado su doctrina como aquella en que la metafísica griega y medieval resulta reasumida alcanzando su formulación más acabada ${ }^{43}$.

41. Ibidem, II.4.1-12, vol. I, 416-423.

42. Ibidem, I.1.29, vol. I, 231-232.

43. M. HeIdegGer, Die Grudprobleme der Phänomenologie, GA Bd. 24 (Klostermann, Frankfurt a. M., 1975) 112: "Suarez ist der Denker, der am stärksten die neuzeitliche Philosophie beinflußt hat. Descartes ist direkt von ihm abhängig, gebraucht 
Para Heidegger, incluso, Suárez habría enfocado el problema metafísico de modo aún más agudo que el propio Tomás o Duns Es$\operatorname{coto}^{44}$, y ello, precisamente, porque el Doctor Eximio ha desechado la ligazón causal entre Creador y creatura como tema concerniente a la metafísica, para relegarlo al ámbito de la sola fe. Presuponiendo que la metafísica es y siempre ha sido por esencia onto-teo-logía, Heidegger considera que admitir en el ámbito metafísico la proveniencia del ente a partir del Ser Primero sería tanto como concebir a Dios como una Ur-Sache, es decir, literalmente, como una causa en el sentido de una proto-cosa productora de otras cosas, lo que, en primer lugar, disminuiría la dignidad del Dios de la fe, y, en segundo, no puede constituir el objeto de reflexión del filósofo, el cual, según habría sido debidamente establecido por Suárez, no tiene por objeto de indagación más que el ente mismo en el sentido del "concepto de ente".

Paradójicamente, entonces, Heidegger expresa su preferencia por la solución de Suárez en comparación con la de Tomás y la de Duns Escoto, mas, en lo que parecería ser una manifiesta con-

fast durchgängig seine Terminologie. Suarez ist es, der die mittelalterliche Philosophie, vor allem die Ontologie, zum erstenmal systematisiert hat. Davor behandelte das Mittelalter, auch Thomas und Duns Scotus, die Antike nur in Kommentaren, die fortlaufend die Texte behandeln. Das Grundbuch der Antike, die 'Metaphysik' des Aristoteles, ist kein zusammenhängendes Werk, hat keinen systematischen Aufbau. Suarez hat das gesehen und suchte, diesem Mangel, als den er das ansah, dadurch abhelfen zu können, da $\beta$ er zum erstenmal die ontologischen Probleme in eine systematische Form brachte, die eine Einteilung der Metaphysik in den folgenden Jahrhunderten bis zu Hegel bestimmte". (Suárez es el pensador que más fuertemente influyó en la filosofía moderna. Descartes depende directamente de él y usa casi generalmente su terminología. Suárez es quien ha sistematizado por primera vez la filosofía medieval, sobre todo la ontología. Antes de ello, la Edad Media, incluido Tomás y Duns Escoto, trataba sobre los autores antiguos sólo en comentarios que consideraban los textos correlativamente. El libro fundamental de los antiguos, la Metafísica de Aristóteles, no es un trabajo coherente; no tiene una estructura sistemática. Suárez vio esto y procuró remediar esta carencia, tal como la consideró, llevando por primera vez los problemas de la ontología a una forma sistemática que determinó una división de la metafísica [en metaphysica generalis u ontología y metaphysica specialis, es decir, cosmologia, psychologia y theologia rationalis] durante los siglos siguientes hasta Hegel).

44. Cfr. ibidem, 113: allí afirma el friburgués que, respecto de la distinción de essentiaexistentia, Suárez es quien "quizás ha visto el problema más aguda y correctamente [am schärfsten und richtigsten]". Omitimos aquí el comentario acerca de los equívocos heideggerianos con respecto a la doctrina tomista indudablemente fundados en la versión del problema transmitida por Egidio Romano. 
tradicción, critica con energía la constitución onto-teo-lógica de la metafísica, estructura que considera veladamente común a toda la filosofía tradicional, pero que, en verdad, habría alcanzado plena expresión recién en las Disputationes suarecianas. Y es que Heidegger no parece advertir que excluir la causalidad creadora de la metafísica en lugar de librarnos de la presunta intromisión de la fe, condujo, históricamente, a la objetivación y a la subsunción de Dios como parte de tal especulación racional.

Por eso, el Friburgués adopta una posición en la que — siguiendo en este punto a Suárez ${ }^{45}$ — el plano ontológico reabsorbe el dato revelado, pues Heidegger cree que el filósofo ha de ajustarse a la mera efectividad óntica, considerándola como el lugar del peculiar ocultamiento de la verdad del ser. Rechaza, por tanto, la metafísica como onto-teo-logía, para, partiendo de un "ateísmo metodológico" — tal como ha querido llamarlo_-, refundar una ontología fundamental, independiente de una ciencia de Dios y, ciertamente, prescindente de la fe. Procura con ello recuperar el ser del ente, entendido incluso como "misterio del ser", pero no por la consideración de su proveniencia a partir del principio creador (ipsum esse), sino por la remisión fenomenológica a su desocultamiento (Unverborgenheit) y despliegue temporal, así como al poder ser llevado a la palabra por el hombre (Dasein). Se intenta, de esa manera, rescatar el misterio del ser del "olvido ontológico" exclusivamente en la dimensión de la finitud temporal.

45. Nos hemos ocupado de la influencia suareciana presente en la lectura heideggeriana de la metafísica, y en particular, de la metafísica medieval, en algunos trabajos precedentes, a saber, Francisco Suárez en la crítica beideggeriana a la metafísica, en AA.VV., América y la idea de la Nueva Humanidad (Sociedad Argentina de Filosofía, Córdoba, 2003, Colección Perspectivas) Tomo IX, 377-384; Heidegger, Aristóteles y la Escolástica, "Sapientia" 217 (2005) 173-184; Francisco Suárez y la transformación del vínculo entre razón y fe. Su repercusión en la filosofía beideggeriana, "Studium. Filosofía y Teología" XIX (2007) 255-268; La posición de Heidegger frente a la ontología medieval: la distinción de esencia y existencia en Tomás de Aquino, Duns Escoto y Francisco Suárez, en AA.VV., Temas de metafísica en la Edad Media (CEFIM, Mendoza, 2011, Cuadernos Medievales de Cuyo no 5) 65-80; Heidegger y Francisco Suárez: buellas de la Escolástica tardía en la interpretación beideggeriana de la metafísica medieval, en C. D'Amico, A. Tursi (eds.), Studium Philosophiae. Textos en bomenaje a Silvia Magnavacca (Rhesis, Buenos Aires, 2014) 184-195. 
Sin embargo, pese a sus errores de apreciación, no puede negarse que Heidegger ha tenido el mérito de reactivar contemporáneamente una revisión de la entera historia de la filosofía, y de señalar, no sin razón, la necesidad de recobrar el ser para el pensar luego de que por largo tiempo resultara completamente eclipsado y asimilado al ente, para acabar, modernamente, bajo el entero dominio de la representación conceptual.

Ahora bien, en cuanto a las metafísicas medievales, dos cosas se han hecho patentes: en primer lugar, que es altamente dudoso, si no francamente falso, que la diversidad histórica de tales doctrinas haya asumido siempre una estructura onto-teo-lógica; y, en segundo término, que la perspectiva adoptada por Heidegger respecto de la tradición filosófica se encuentra notoriamente influida y traspasada por la Escolástica tardía. Esta óptica preferencial ha condicionado, sin duda, la visión y el juicio contemporáneo sobre la tradición metafísica, así como el modo en que, en lo sucesivo, se ha planteado la pregunta por el ser del ente y la naturaleza del pensar filosófico.

\section{REFERENCIAS}

Avicena, Liber de philosophia prima, sive scientia divina (Peeters/Brill, Louvain-la-Neuve/Leiden, 1983).

O. Boulnois, Heidegger, l'ontothéologie et les structures médiévales de la métaphysique, en C. EsPosito, P. Porro (eds.), Quaestio 1. Heidegger e i medievali (Brepols-Pagina, Turnhout-Bari, 2001) 379-406.

J. D. CAPuTo, Heidegger and Aquinas. An Essay on Overcoming Metaphysics (Fordham University Press, New York, 1982).

J.-F. Courtine, Heidegger et Thomas d'Aquin, en C. Esposito, P. Porro (eds.), Heidegger e i medievali, "Quaestio. Annuario di storia della metafísica” 1 (2001) 213-234.

J.-F. Courtine, Inventio analogiae. Métaphysique et ontothéologie (Vrin, Paris, 2005).

O. N. DERISI, Reflexiones acerca del sentido del esse en Santo Tomás frente a la concepción respectiva en Aristóteles, en la Escolástica y en Heidegger, "Sapientia" (La Plata) 14 (1959) 289-292. 
O. N. DERISI, El ser en Heidegger y Santo Tomás (EUDEBA, Buenos Aires, 1968).

O. N. DERISI, El último Heidegger. Aproximaciones y diferencias entre la fenomenología existencial de M. Heidegger y la ontología de Santo Tomás (EUDEBA, Buenos Aires, 1968, Col. Ensayos).

A. Dondeyne, La différence ontologique chez M. Heidegger, "Revue Philosophique de Louvain" 56, 49 (1958) 35-62.

JuAn Duns Escoto, Quaestiones in Metaphysicam I, q. 1, n. 43, 142, ed. G. ETZKORN et al. (St. Bonaventure University, The Franciscan Institute, St. Bonaventure, NY, 1997).

R. ECHAURI, La diferencia ontológica en Heidegger y Santo Tomás, "Philosophia” 28 (1964) 15-28.

R. ECHAURI, Heidegger y la metafísica tomista, con Prefacio de É. GILSON (EUDEBA, Buenos Aires, 1971).

R. EChauri, Parménides y el ser, "Anuario Filosófico" 6 (1973) 98115.

R. ECHAURI, Heidegger y el esse tomista "Cuadernos de Filosofía" XI/15-16 (1971) 207-214.

R. ECHAURI, Sobre una nueva confrontación de Heidegger con Santo Tomás, "Sapientia" 42 (1987) 371-380.

R. ECHAURI, Esencia y existencia (CUDES, Buenos Aires, 1990).

R. ECHAURI, Sobre el origen del ser y la nada, "Acta Philosophica" 3/2 (1994) 315-325.

C. Esposito, Ritorno a Suárez. Le Disputationes Metaphysicae nella critica contemporanea, en La Filosofia nel Siglo de Oro. Studi sul tardo rinascimento spagnolo (Levante Editori, Bari, 1995) 465573.

C. Esposito, Heidegger, Suárez e la storia dell'ontologia, en C. EsPOsito, P. PORRo (eds.), Quaestio 1. Heidegger e i medievali (Brepols-Pagina, Turnhout-Bari, 2001) 407-430.

C. FABRo, L'interpretazione del'atto in S. Tommaso ed Heidegger (Edizioni Domenicane Italiane, Napoli, 1975).

C. FABro, Santo Tomás frente al desafío del pensamiento moderno, en C. FABRo et al., Las razones del tomismo (EUNSA, Pamplona, 1980).

S. FILIPPI, Francisco Suárez en la crítica beideggeriana a la metafísica, en 
AA.Vv., América y la idea de la Nueva Humanidad (Sociedad Argentina de Filosofía, Córdoba, 2003, Colección Perspectivas) Tomo IX, 377-384.

S. FILIPPI, Heidegger, Aristóteles y la Escolástica, "Sapientia" 217 (2005) 173-184.

S. FILIPPI, Francisco Suárez y la transformación del vínculo entre razón y fe. Su repercusión en la filosofía beideggeriana, "Studium. Filosofía y Teología” XIX (2007) 255-268.

S. FILIPPI, La posición de Heidegger frente a la ontología medieval: la distinción de esencia y existencia en Tomás de Aquino, Duns Escoto y Francisco Suárez, en AA.VV., Temas de metafísica en la Edad Media (CEFIM, Mendoza, 2011, Cuadernos Medievales de Cuyo $\mathbf{n}^{\mathbf{o}}$ 5) 65-80.

S. FILIPPI, Heidegger y Francisco Suárez: huellas de la Escolástica tardía en la interpretación heideggeriana de la metafísica medieval, en C. D'Amico, A. Tursi (eds.), Studium Philosophiae. Textos en bomenaje a Silvia Magnavacca (Rhesis, Buenos Aires, 2014) 184-195.

S. FILIPPI, Causalidad y creación en la metafísica tomista. Notas sobre una equívoca interpretación heideggeriana, en L. CORSO DE ESTRADA, M. J. Soto-Bruna, C. Alonso Del Real (eds.), Figuras de la causalidad en la Edad Media y en el Renacimiento (EUNSA, Pamplona, 2017, Colección de Pensamiento Medieval y Renacentista) 425-439.

É. GILSON, Constantes philosophiques de l' être (Vrin, Paris, 1983).

M. HeIDEgGer, Was ist Metaphysik? (Klostermann, Frankfurt a. M., 1955).

M. Heidegger, Identität und Differenz (Neske, Pfullingen, 1957).

M. Heidegger, Nietzsche, Bd. II (Neske, Pfullingen, 1961).

M. HeIDEgGer, Die Grudprobleme der Phänomenologie, GA Bd. 24 (Klostermann, Frankfurt a. M., 1975).

M. HeIdegger, Hegels Phänomenologie des Geistes, GA Bd. 32 (Klostermann, Frankfurt a. M., 1980).

M. HeIDegGer, Grundbegriffe der Metaphysik. Welt-EndlichkeitEisamkeit, Freiburger Vorlesung WS 1929/30, GA Bd. 29/30 (Klostermann, Frankfurt a. M., 1983). 
M. HeIdegger, Kant und das Problem der Metaphysik, GA Bd. 3 (Klostermann, Frankfurt a. M., 1991).

G. LLACH, Heidegger y su interpretación del esse tomista, "Aporía. Revista Internacional de Investigaciones Filosóficas” 6 (2013) 47-58.

J. LotZ, Heidegger und Thomas von Aquin (Herder, Freiburg, 1975). MAIMÓNIDES, Guía de los perplejos, 3 vols., versión española de L. DujOVNE (Consejo Nacional para la Cultura y las Artes, México, 1993). J.-L. MARIOn, Dieu sans l'être (Fayard, Paris, 1982-rééd. PUF, Paris, 2010).

M. MÜLLER, Sein und Geist. Systematischen Untersuchungen über Grundprobleme und Aufbau mittelalterliche Ontologie (Mohr, Tübingen, 1940), $2^{a}$ ed. ampliada con la contribución Die Aktualität des Thomas von Aquin (Karl Alber, Freiburg/München, 1981).

B. Rioux, L'être et la vérité chez Heidegger et Saint Thomas d'Aquin (Presses de l'Université de Montréal-Presses Universitaires de France, Montreal-Paris, 1963).

G. SiEWERTH, Das Schicksal der Metaphysik von Thomas zu Heidegger (Johannes Verlag, Einsiedeln, 1959).

Siger de Brabante, Quaestiones in Metaphysicam, ed. C. A. GraifF (Éditions de l'Institut Supérieur de Philosophie, Louvain-laNeuve, 1948).

Siger De Brabante, In Metaphysicam IV Commentarium, ed. W. Dunphy (Éditions de l'Institut Supérieur de Philosophie, Louvain-la-Neuve, 1981).

J. Stallmach, Der actus essendi bei Thomas von Aquin und das Denken der "ontologischen Differenz", "Archiv für Geschichte der Philosophie" 50/1-2 (1968) 134-144.

Francisco SuÁreZ, Disputaciones metafísicas, ed. bilingüe a cargo de S. Rábade Romeo, S. Caballero Sánchez, A. Puigcerver ZANÓN (Gredos, Madrid, 1960-1967) 7 vols.

Tomás de Aquino, In duodecim libros Metaphysicorum Aristotelis expositio (Marietti, Torino-Roma, 1950).

Tomás DE Aquino, In librum de Causis expositio (par H. D. SAFFreY, Société Philologique, Textus philosophici friburgenses (4/5), Édition E. Nauwelaerts, Louvain, 1954). 


\section{BIBLIOGRAFÍA}


